\title{
La clase social en los libros de texto de ELE
}

\author{
Pau Bori - Universidad de Belgrado \\ pau.bori.sanz@fil.bg.ac.rs \\ Ana Kuzmanović Jovanović - Universidad de Belgrado \\ akuzmanovic@fil.bg.ac.rs
}

Rebut / Received: 23/11/19

Acceptat / Accepted: 30/01/20

Resum. La classe social als llibres de text d'ELE. Aquest article examina les representacions discursives de la classe social en dues col-leccions de llibres de text d'espanyol com a llengua estrangera (ELE) publicades en dos períodes diferents: els anys setanta del segle passat i la segona dècada del segle XXI. Es duu a terme una anàlisi crítica del discurs per revelar les connotacions ideològiques dels llibres de text en les seves visions de l'individu i la societat. Els resultats mostren que la col-lecció dels setanta, influenciada per plantejaments marxistes, emfatitza la divisió social en dues classes antagòniques: la capitalista i la treballadora. En canvi, els llibres de text més recents, publicats en una fase de consolidació neoliberal, camuflen l'existència d'una societat classista i es fan ressò del discurs meritocràtic dominant, segons el qual cada persona pot arribar fins allà on es proposi, sense importar les desigualtats estructurals del sistema.

Paraules clau: llibres de text, espanyol com a llengua estrangera (ELE), classe social, neoliberalisme, marxisme.

\begin{abstract}
Social class in textbooks of Spanish as a foreign language. This article examines the discursive representations of the social class in two series of Spanish as a foreign language (SFL) textbooks published in two different periods: the 1970 s and the second decade of the $21^{\text {st }}$ century. A critical discourse analysis was carried out to reveal the ideological connotations of textbooks in their views of the individual and society. The results show that the collection from the 1970s, influenced by Marxist approaches, places great emphasis on the division of society into two antagonistic classes: the capitalists and the working class. On the other hand, the most recent textbooks, published in a consolidation phase of neoliberalism, camouflage the existence of a class society and echo the dominant meritocratic discourse, according to which each person can accomplish their aims and fulfill their objectives, regardless of the structural inequalities of the system.
\end{abstract}


Keywords: textbooks, Spanish as a foreign language (SFL), social class, neoliberalism, Marxism.

\section{Introducción}

El libro de texto sigue desarrollando un rol protagonista en muchas aulas de idiomas de todo el mundo, a pesar de la multitud y variedad de recursos disponibles en línea. A menudo es la base del programa del curso, sirve de guía o fuente de inspiración para docentes y determina actividades e interacciones dentro de la clase (Chapelle, 2016). Como señala Apple (2004) para la educación en general, el libro de texto tiene una función muy importante en el aula ya que, seleccionando y legitimando ciertos conocimientos y formas culturales, y al mismo tiempo censurando otros, representa un poderoso mecanismo para transmitir ideologías.

Los estudios sobre libros de texto de español como lengua extranjera (ELE) han indagado tradicionalmente cuestiones metodológicas, como la integración de aspectos gramaticales y culturales, su adecuación a un perfil determinado de aprendices, o su idóneo uso en el aula (v. de Pablos-Ortega, 2018 para un panorama general de las investigaciones sobre materiales didácticos de ELE). Sin embargo, el contenido ideológico y su vinculación al contexto político y económico se han tendido a ignorar en los análisis, a pesar de su potencial para aportar una mejor comprensión de los libros de texto. De hecho, diversos estudios han demostrado la relevancia de un enfoque político y económico para revelar, por ejemplo, el énfasis en el individualismo y el consumismo en materiales didácticos actuales para la enseñanza del inglés (p. ej., Babaii y Sheikhi, 2018; Bori, 2020; Chun, 2009; Gray, 2010), y también del francés (Block y Gray, 2018) o del catalán (Bori, 2018, 2019). Siguiendo esta perspectiva, recientemente hemos examinado el contenido relacionado con el mundo del trabajo en libros de texto de ELE (Bori y Kuzmanović Jovanović, en prensa). Los resultados de este estudio indican que las representaciones laborales en los libros de texto vienen condicionadas por cambios en la esfera económica y material de la sociedad. Así, a partir de la década de los noventa, coincidiendo con el auge del neoliberalismo como paradigma económico, político e ideológico dominante, el contenido laboral de los libros de texto está cada vez más asociado con prácticas y valores neoliberales como el emprendimiento, la competitividad, el individualismo, la flexibilidad o la empleabilidad.

El presente artículo profundiza esta línea de investigación con un análisis que sitúa en el centro de su interés el concepto de clase social en dos colecciones de libros de texto de ELE publicadas en España en periodos distintos: los setenta del siglo pasado y la segunda década del siglo XXI. ${ }^{1}$ En concreto, analizamos discursivamente las representaciones sobre la clase social en el contenido de estas dos colecciones con el propósito de revelar

1. Una primera versión de este artículo fue presentada en una ponencia en el XIII Simposio Internacional de la SEDLL, celebrado en la Facultad de Filología de la Universidad de Belgrado (20-22 de junio de 2019). 
su trasfondo ideológico y enlazar los cambios identificados en los libros de texto con la irrupción de un nuevo orden político, económico e ideológico, tanto en España como a nivel global, el neoliberalismo.

\section{Clase social y neoliberalismo}

Marx es a menudo considerado el punto de partida para definir la clase social, si bien influyentes autores como Weber o Bourdieu desarrollaron después este concepto (ver Block, 2014 para un recorrido histórico sobre las principales concepciones de clase social). La definición marxista de clase social se diferencia de las posteriores al considerarla esencialmente como una relación antagónica entre poseedores y no poseedores de los medios de producción, de la que surge la lucha de clases (Callinicos, 1995). Por tanto, la clase es una relación empírica que no depende de percepciones subjetivas, sino de la posición de cada persona en las relaciones de producción (Callinicos, 1995).

A medida que el sistema capitalista cambia, desaparecen ciertos trabajos y se crean otros. Si la clase trabajadora en la época de Marx estaba formada por obreros fabriles, ahora en Europa se encuentra sobre todo en el sector de servicios. Por su parte, los representantes de la clase capitalista ya no serían tanto los patrones de las fábricas sino los accionistas de grandes multinacionales. Aunque el marxismo distingue dos clases sociales, incluye matices en esta división. De hecho, el mismo Marx mencionó la pequeña burguesía (Marx y Engels, 1848/2018), lo que hoy llamaríamos clase media. Está compuesta por algunos trabajadores autónomos y profesiones liberales (maestros y profesores, trabajadores sociales, médicos, etc.). Esta clase media no sería la capitalista, ya que no extrae plusvalía del trabajo de sus empleados, pero tampoco encajaría dentro de la clase trabajadora por no proporcionar directamente con su fuerza de trabajo una plusvalía al capitalista (Hill, 2017). Sin embargo, sus condiciones laborales y sus salarios han sido precarizados con la progresiva pérdida de autonomía, estatus socioeconómico, e incluso con la constante amenaza de pérdida de trabajo, por lo que se la debería considerar como parte de la clase trabajadora (Hill, 2017). En resumen, desde una perspectiva marxista, hay dos clases sociales: la trabajadora con componentes de la clase media, lo que podríamos denominar las clases populares, que siempre son la mayoría de la población en todos los países; y, por otro lado, una minoría, la clase capitalista, propietaria de los medios de producción y distribución, aliada con las élites de los partidos políticos dominantes y los propietarios de los grandes medios de información (Navarro, 2013).

Junto con la clase social, el neoliberalismo es el otro concepto clave para nuestro marco teórico. A pesar de que existen diferentes interpretaciones del neoliberalismo y sin desdeñar que es un fenómeno complejo y dinámico, en este estudio lo entendemos como la política económica y la ideología dominantes del sistema capitalista en las últimas cuatro décadas (Harvey, 2005). El neoliberalismo hace referencia a un conjunto de políticas económicas que proponen la desregulación de los mercados, la privatización de los servicios públicos, una reducción de impuestos a las rentas más altas y la configuración 
de un marco jurídico y político que proteja el libre comercio, la competencia, la propiedad privada y la iniciativa individual. El neoliberalismo, a su vez, es la ideología (conjunto de valores y creencias) en la que se sustenta este nuevo orden político y económico. Como ideología, el neoliberalismo entiende el mercado como principio fundamental de la sociedad humana y prioriza el individuo por encima de los colectivos. Por consiguiente, enfatiza la libertad y responsabilidad personales, y venera los individuos más competitivos y emprendedores. En este sentido, el neoliberalismo ve "la pobreza y el desempleo ya no como problemas sociales, sino más bien como fracasos individuales" (Jones, 2016, p. 9). Esta última idea está conectada con el ascenso del discurso meritocrático neoliberal, según el cual cada persona tiene lo que merece, en función de su esfuerzo y talento, sin importar las desigualdades estructurales existentes (Littler, 2018).

El neoliberalismo así concebido está íntimamente conectado con la definición marxista de clase. Por un lado, de acuerdo con Harvey (2005), el programa neoliberal debería ser entendido como una lucha de clases desde arriba, en el sentido de que fue un proyecto político de las cúpulas del poder económico mundial para recuperar la rentabilidad del capital después de la crisis económica internacional de los setenta. La implementación de políticas neoliberales ha implicado un incremento de las desigualdades sociales (Harvey, 2005), que han aumentado aún más desde el comienzo de la crisis económica de 2007 (Block, 2018). Por otro lado, la ideología neoliberal emana de los puntos de vista de las clases sociales dominantes (Harvey, 2005), si bien es cierto que en su configuración participa también un amplio espectro de instituciones, organizaciones y colectivos (Larner, 2000). Finalmente, y este es el punto más relevante para nuestro análisis, el neoliberalismo considera la clase social como un concepto anacrónico, e incluso "una categoría ficticia que solo existe en la imaginación de socialistas y cripto-comunistas" (Harvey, 2005, p. 202). El mantra neoliberal de "ahora todos somos clase media" tiene como objetivo diluir el sentimiento de clase e imposibilitar así comprender las razones de la distribución desigual de la riqueza (Jones, 2016).

\subsection{La clase social en la enseñanza y los materiales didácticos de idiomas}

Las investigaciones críticas sobre educación de idiomas se iniciaron en los ochenta (Canagarajah, 2005), pero ha sido solo recientemente cuando ha habido un mayor interés por la clase social en este ámbito. En su lugar, se ha indagado en la interculturalidad y en cuestiones de identidad en base al género, la raza o la orientación sexual. Esta tendencia se enmarca dentro de una corriente general de la lingüística aplicada (y del conjunto de las ciencias sociales y las humanidades) que a partir de los ochenta consideró reduccionista focalizarse en la estructura social para comprender la complejidad de las sociedades modernas (Block, 2015). La exclusión de la clase social en el mundo académico coincidió con el auge del neoliberalismo como paradigma ideológico dominante, con su celebración del individuo y su falta de interés por los colectivos sociales (Block, 2015). 
Después del inicio de la crisis económica mundial en 2007, cada vez son más los autores que destacan la relevancia de la clase social en estudios de lingüística aplicada (Block, 2014, 2015), y sobre enseñanza de idiomas en particular: ver, por ejemplo, el número especial del Journal of Language, Identity, and Education sobre clase social y enseñanza del inglés (Kanno y Vandrick, 2014). Los estudios sobre materiales didácticos de lenguas extranjeras, siguiendo la tendencia general de las investigaciones sobre educación de idiomas, no han solido tomar en consideración la clase social. No obstante, debemos destacar los trabajos de Auerbach y Burgess (1985) y Kinginger (2004), que demostraron que los libros de texto de idiomas analizados no consideraban la situación socioeconómica de los aprendices que los utilizaban al presentar únicamente valores y prácticas de las clases dominantes. Más recientemente, varios autores han focalizado sus análisis sobre materiales didácticos de idiomas en esta cuestión. Gray y Block (2014) y Copley (2018) examinan libros de texto de inglés, mientras que Bori (2018) estudia materiales didácticos de catalán como lengua extranjera. Estos tres estudios coinciden en destacar la influencia del neoliberalismo en la ocultación de la división por clases en los materiales actuales, así como en su énfasis en el consumismo y el individualismo.

\section{Metodología y corpus}

Partiendo de la premisa metodológica de Fairclough (1992), según la cual los cambios en el orden discursivo se pueden relacionar con cambios sociales más generales, nuestro análisis identifica transformaciones respeto a la representación de la clase social en el contenido de libros de texto de ELE. Al situar la clase social y el neoliberalismo en el centro de nuestro interés, el presente artículo responde al reciente llamamiento de Fairclough (2014) para que el Análisis Crítico del Discurso vuelva a su vinculación originaria con el marxismo y el conflicto de clases. Según Fairclough (2014, p. 2), para que los estudios del discurso sean realmente críticos, es necesario tener en cuenta que el discurso no solo tiene una estructura interna, sino que también participa y es un espacio de "lucha social", la cual incluye "la lucha de clases".

Dentro del Análisis Crítico del Discurso, este estudio se basa en una de las herramientas metodológicas desarrolladas por el Enfoque Histórico del Discurso (Wodak, 2007). En primer lugar, buscamos referencias, tanto directas como indirectas, y tanto textuales como visuales, a la estructuración social, tomando en consideración las voces de los autores y los protagonistas de los textos. En segundo lugar, identificamos las estrategias discursivas utilizadas en el corpus para la creación de significados sobre el concepto de clase y la estratificación social. Wodak (2007, p. 195) define las estrategias como "un plan más o menos preciso y más o menos intencional (incluyendo las prácticas discursivas) adoptado para alcanzar un objetivo social, político, psicológico o lingüístico particular”. El énfasis del análisis se sitúa especialmente en las siguientes cinco estrategias discursivas expuestas por Wodak (2007): 
- Nominación: ¿Cómo se nombran y se refieren las personas (o grupos de personas)?

- Predicación: ¿Qué características, rasgos distintivos y cualidades (positivas o negativas) se les atribuyen?

- Argumentación: ¿Qué argumentos se utilizan para justificar o legitimar a ciertos grupos sociales, excluir a otros, y explicar las distintas posiciones sociales que estos ocupan?

- Perspectivización: ¿Desde qué punto de vista se expresan los argumentos?

- Intensificación o mitigación: ¿Cómo se incrementa o atenúa la fuerza ilocutiva de las afirmaciones?

La herramienta metodológica desarrollada en el presente estudio permite un análisis sistemático y transparente sobre la representación discursiva de la clase y la estratificación social que podría ser aplicado en un futuro a otros libros de texto. Además, al situar cada discurso dentro de su contexto histórico, el análisis posibilita explorar la transformación de las estrategias discursivas a lo largo del tiempo.

El corpus de nuestro estudio está formado por dos colecciones de libros de texto de ELE para aprendices adultos:

- Español en directo Nivel 1A, 1B (Sánchez, Ríos y Domínguez, 1974, 1975), Nivel 2A, $2 B$ (Sánchez, Cabré y Matilla, 1975, 1976) y Nivel 3 (Sánchez, 1977).

- Nuevo Prisma A1, A2, B1, B2 (Equipo Nuevo Prisma, 2013a, 2013b, 2015a, 2015b).

Hemos seleccionado estas colecciones por dos motivos:

a. Ambas tienen (o tuvieron) una importante divulgación nacional e internacional (en academias de idiomas y universidades). En la época en que se publicó Español en directo había pocos libros de texto de ELE, lo que favoreció su amplio uso en las aulas. Otras razones que podrían explicar su difusión son estas: la novedad que representó al introducir por primera vez el método estructural-situacional en un material de ELE; su sencillez, que permitía una fácil implementación en la clase; y su visión transversal de la sociedad española de los setenta (Aquilino Sánchez, comunicación personal, 2020). Además, cabe destacar la cualidad de su contenido, especialmente en el último volumen, que incluye un amplio abanico de temas a través de textos extensos y profundos sobre geografía, historia, sociología, economía, política, arte, filosofía o cultura popular. Nuevo Prisma, en cambio, ha visto la luz en un periodo de gran oferta de libros de texto de ELE. $\mathrm{Su}$ amplia divulgación responde, en gran parte, a que su editorial, Edinumen, es una de las principales empresas editoras de materiales didácticos de ELE con unas potentes herramientas de promoción y difusión. Su catálogo se vende en los cinco continentes a través de una red de más de 60 distribuidores.

b. Pertenecen a dos periodos distintos (una es anterior a la etapa neoliberal en Espańa y la segunda ha sido publicada en un periodo de consolidación neoliberal), con lo que podremos comparar los resultados a la luz de las transformaciones recientes del capitalismo. 


\section{Análisis}

\subsection{División social por clases}

Español en directo, publicada antes del inicio de la etapa neoliberal en España, hace énfasis en la división social por clases. Así, en una reseña del libro Estructura de clases en la España actual se argumenta que "la existencia de una acusada desigualdad social continúa siendo uno de los rasgos más característicos de nuestra realidad social" (Sánchez et al., 1976, p. 102). Más adelante, otro texto se sirve de la estrategia discursiva de la argumentación aportando datos sobre la insuficiencia salarial de los trabajadores ante el coste de la vida para concluir que en España no se ha logrado "una distribución igualitaria de los ingresos por el trabajo" (Sánchez, 1977, p. 164). El texto está ilustrado por dos caricaturas (un joven albañil y un señor caracterizado según el arquetipo burgués), que observamos en la Imagen 1. Desde el punto de vista de las estrategias de nominación y predicación, estas caricaturas se refieren a dos clases sociales claramente diferenciadas (la trabajadora y la capitalista) y atribuyen a cada una rasgos estereotipados.

El conflicto social entre dos clases antagónicas está representado a través de una viñeta que empieza con una mujer reflexionando: "Que yo sepa los pobres tenemos siempre crisis económica ". Y, a continuación, siguen las exclamaciones indignadas de la mujer: "¡Y los ricos nunca se han enterado .! Cuando los ricos tienen mal momento jlos primeros en enterarnos somos los pobres .!" (Sánchez, 1977, p. 161). Al expresar el punto de vista de un miembro de la clase trabajadora, el texto de la vińeta utiliza una estrategia de perspectivización para acompañar un artículo que informa que "España ha padecido en 1975 una tasa de inflación superior a la media de los países europeos de la OCDE".
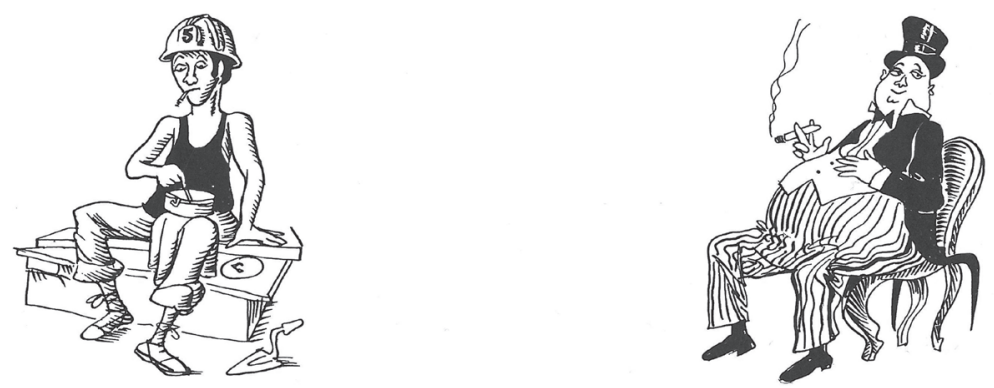

IMAGEN I. (SÁNCHEZ, I977, P. I64).

Encontramos de nuevo la nominación de dos clases claramente diferenciadas en un texto titulado "El turismo del rico... Y el turismo del pobre" (Sánchez, 1977, pp. 179180). A través de la predicación, sobre el rico se explica que su "aspiración máxima es convertirse en veraneantes de toda la vida y el mayor temor es que los advenedizos 
(generalmente la clase inferior) lleguen a ser muy numerosos y hagan descender el 'tono' del ambiente". Respeto al turismo del pobre, se dice: "Apenas si es posible disfrutar de lo que se visita o se ve; pero los turistas pueden tener la satisfacción de contar a sus compańeros de trabajo, cuando vuelvan, que han estado en tal o cual sitio". El texto va acompañado por dos ilustraciones que intensifican los atributos presentados en el texto: una de un señor de barriga enorme en bañador con un cóctel en la mano tumbado sobre un flotador en una piscina, y otra de un joven durmiendo en una hamaca bajo la sombra de un árbol, con una botija y un matamoscas al lado.

Otros ejemplos de predicación de estas dos clases hacen referencia al mundo laboral. En un diálogo con su esposa, un empleado de oficina anuncia que no quiere levantarse de la cama para ir a trabajar porque está harto de su empleo (Sánchez et al., 1975a, p. 17). Por otro lado, más adelante encontramos un diálogo entre un médico y un empresario que, a pesar de estar enfermo, quiere volver al trabajo: "Si me quedo en casa una semana, me arruinaré. Mis empleados no saben hacer nada sin mí. (...) No quiero perder dinero" (Sánchez et al., 1975a, p. 23). Cuando el médico le pregunta para qué quiere tanto dinero, el empresario responde: "Nunca me he contentado con poco". Ilustra esta última afirmación un dibujo del empresario sonriendo en la cama imaginando montones de billetes y bolsas de dinero, lo que representa un nuevo ejemplo de intensificación de las características expuestas en el diálogo.

La estrategia de predicación para atribuir características negativas (en este caso, la codicia) no se utiliza únicamente para representar la clase capitalista. La encontramos también para describir a personajes asalariados, como es el caso de "dos concuñados, vallisoletanos y peones", que "han descubierto el secreto para trabajar diecinueve horas diarias", con el objetivo de pagar todo lo que han comprado y adquirir un "seiscientos" (Sánchez et al., 1976, pp. 73-74). Durante el día descargan cajas de electrodomésticos y, por la noche, hacen de vigilantes en la misma empresa. El patrón accedió a darles un doble empleo en agradecimiento por haber sido los únicos que trabajaron durante una huelga laboral. Es relevante destacar que estos concuñados, que hoy en día serían un paradigma del trabajador neoliberal ideal por su flexibilidad y por anteponer los intereses de la empresa a los derechos colectivos, son presentados en esta colección a través de una estrategia de perspectivización al explicar su historia desde un punto de vista burlesco y, además, se intensifica su presentación negativa al destacar que son vistos "con mala cara" por sus compañeros de trabajo.

Español en directo ahonda en la división de la sociedad en clases a través de un texto sobre enseñanza pública y privada (Sánchez, 1977, pp. 233-234). Se pregunta si "es posible una auténtica igualdad de oportunidades en el marco de una sociedad clasista”. La respuesta ofrecida es una cita de un libro del sociólogo marxista Ignacio Fernández de Castro:

La igualdad de oportunidades en la enseñanza no rompe en absoluto el sistema de reproducción de la relaciones capitalistas de producción: el no-propietario asalariado, cualquiera que sea el nivel de instrucción que haya logrado adquirir, seguirá siendo no- 
propietario asalariado; el propietario de los medios de producción, aunque no tenga instrucción ni la más pequeña formación profesional, seguirá siendo propietario de los medios de producción.

Desde el punto de vista de las estrategias discursivas, el texto nomina dos clases sociales (el propietario y el no-propietario de los medios de producción) y argumenta que la reproducción de las relaciones capitalistas de producción es la causa principal de la desigualdad social existente. Tanto esta argumentación como el resto de estrategias discursivas sobre la clase social de esta colección son indicativas de la influencia que la teoría marxista tenía entonces en las ciencias sociales y las humanidades. En España, por ejemplo, dos de los filósofos más destacados eran marxistas: Manuel Sacristán y Francisco Fernández Buey. También en aquel momento se desarrollaron en España análisis literarios marxistas, influenciados por autores como Lukács, Sartre y Williams, muy leídos en la época (frecuentemente en ediciones latinoamericanas), y, en el ámbito educativo, fue muy popular Gramsci y su concepto de hegemonía (Francesc J. Hernàndez, comunicación personal, 2019). Uno de los autores de la colección, el profesor Aquilino Sánchez (comunicación personal, 2020), recuerda que "los textos se eligieron teniendo en cuenta las preocupaciones y sentir del momento, pero con el claro objetivo de aprender la lengua a través de ellos". Sánchez también apunta que, aunque "el punto de vista es lingüístico, no ideológico", la obra "naturalmente, reflejará, al menos parcialmente, el pensamiento de la época” en torno a las cuestiones tratadas en este artículo.

\subsection{Sociedad meritocrática}

A diferencia de la colección de los setenta, en la que se representa una sociedad en conflicto entre dos clases, los libros de texto actuales presentan un panorama social muy diferente. El discurso que ahora predomina es el meritocrático, según el cual no importa la posición social que uno ocupa al nacer, ya que la sociedad ofrece oportunidades de movilidad social a las personas con talento que se esfuercen lo suficiente. El talento, combinado con el empeño, es el elemento principal de este discurso meritocrático, dominante en las sociedades neoliberales (Littler, 2018). En otras palabras, se recurre a la nominación de solo una clase social, la meritocrática, formada por individuos que triunfan en la sociedad gracias a sus destrezas y esmero.

Un ejemplo paradigmático de combinación de esfuerzo y éxito individuales sería el de José Manuel Anguiano, un joven "con un objetivo muy claro: perseguir un sueño" (Equipo Nuevo Prisma, 2015b, pp. 16-17). Hablando de su trabajo, José Manuel destaca que "no es una empresa, sino un sueño, un sueño ya hecho realidad". En su conclusión, el texto argumenta: "Con su trabajo, lo que nos ha demostrado este joven director es que hacer lo que de verdad te gusta, apasionarte con todo lo que haces y disfrutar de ello, es posible y, sobre todo, que vale la pena intentarlo". 
Otro mensaje importante que transmiten estos libros de texto es la importancia de ser atrevido y arriesgarse como única forma de conseguir el éxito en la sociedad contemporánea. Así, por ejemplo, en un texto de Nuevo Prisma (2015a, p. 135), a través de la predicación, se explica que, como somos "seres atrevidos, valientes y aventureros", queremos mejorar nuestra condición vital y, por eso, corremos riesgos. En este discurso meritocrático, el riesgo no es presentado como algo negativo (o peligroso), sino motivador, positivo e imprescindible para prosperar. Además, cada persona debe ser responsable de asumir individualmente los riesgos que le corresponden. No hay referencia a estructuras económicas y sociales que impiden que muchas personas no puedan abrirse camino, ya que todo depende de saber tomar riesgos. Es decir, en vez de apuntar a las desigualdades estructurales del sistema económico, este discurso argumenta que tanto el éxito como el fracaso dependen del esfuerzo personal. Se trata, sin duda, de un discurso profundamente individualista.

Un personaje típico de esta colección sería Enrique, un alpinista argentino que viaja al Everest una vez al año (Equipo Nuevo Prisma, 2015b). Enrique es uno de los muchos ejemplos de personajes aventureros y atrevidos, que persiguen sus sueños (los que, por cierto, casi siempre suponen importantes recursos económicos, como en este caso). En Nuevo Prisma abundan también ejemplos de historias de éxito personal, de individuos de origen humilde que consiguieron triunfar gracias a su ahínco, donde leemos expresiones como las siguientes: "camino largo de sacrificio", "fue muy duro", "hubo muchos momentos difíciles" y "nunca antes me había sentido tan orgullosa” (Equipo Nuevo Prisma, 2015b, p. 42; 2015b, p. 46). También es relevante que, en la mayoría de fotos, la gente aparece sonriente, guapa y bien vestida, con la división por clases y la pugna entre ellas totalmente borradas, como ilustra, por ejemplo, la Imagen 2.

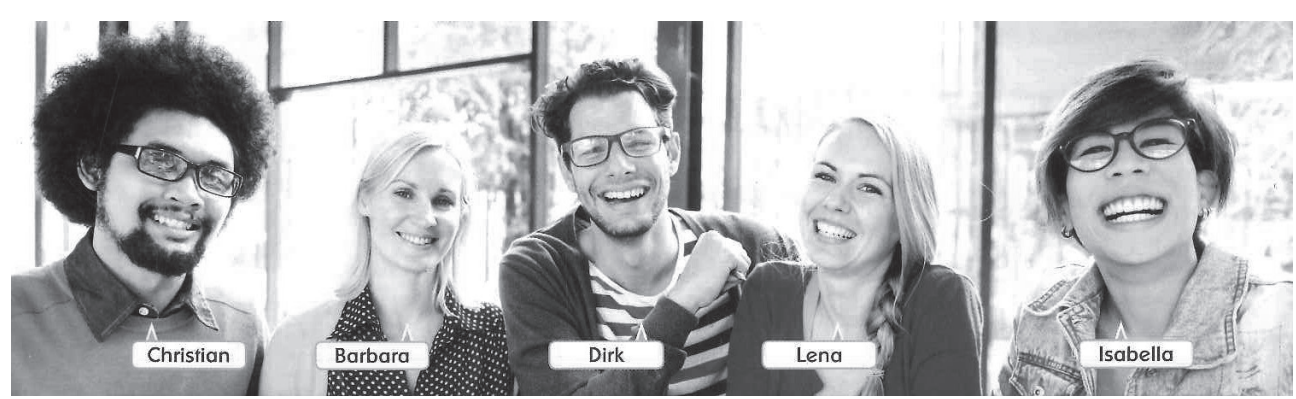

Imagen 2. (Equipo Nuevo Prisma, 20 i 5 B, P. 22).

Los libros de texto actuales no solo muestran ejemplos de cómo el esfuerzo personal lleva al éxito, sino que también enseñan al alumnado cómo conseguirlo. Un buen ejemplo de ello es una serie de textos en los que se instruye al alumnado a buscar logros profesionales. Por ejemplo, un texto corto, "Las carreras con mayor 
futuro" (Equipo Nuevo Prisma, 2015a, p. 68), versa sobre las "titulaciones más valoradas", entre las que destacan empresariales, económicas, administración y dirección de empresas. Después de incitar a los alumnos a reflexionar y discutir sobre su futuro laboral, se les enseña a escribir diferentes géneros discursivos, como la carta de presentación, motivación o el curriculum vitae, para aumentar sus posibilidades de éxito profesional. Entre los textos de este tipo, el más llamativo es un discurso de Steve Jobs en el que habla de su experiencia universitaria (Equipo Nuevo Prisma, 2015b, p. 70). Del texto se deduce que cada persona es una microempresa individual: debe actuar de acuerdo con los principios empresariales de eficiencia, competitividad y flexibilidad, y saber tomar iniciativas arriesgadas. De esta forma, se argumenta que cualquier persona puede triunfar, sin importar las condiciones socioeconómicas. En el marco de este discurso individualista, se hace también hincapié en el cuidado del yo, específicamente en el cuidado del cuerpo. Nuevo Prisma ofrece muchos consejos para esta clase de cuidados. En los textos de este tipo predomina el léxico relacionado con el "bienestar": salud, moda, vida social, diversión, relajamiento, etc. Así, en un texto corto, se recomienda: "haz ejercicio, descansa, relájate, visita a tu médico, lleva una dieta sana y variada, evita el tabaquismo y el alcoholismo, convive" (Equipo Nuevo Prisma, 2015b, p. 51). En su mayoría, se trata de consejos restringidos a solo una parte de la sociedad, la acomodada, con trabajo y dinero, y sin preocupaciones para llegar a fin de mes.

En cambio, las referencias a las desigualdades sociales y económicas existentes son marginales, suavizadas y siempre indirectas. Por ejemplo, hay una audición en la que se presenta la historia de un chico español que se fue al extranjero para buscar trabajo y lo consiguió, aunque, en vez de trabajar como ingeniero, hace de camarero (Equipo Nuevo Prisma, 2015a, p. 21). La historia está contada en forma de diálogo entre el chico y su madre desde una perspectiva que no cuestiona la situación socioeconómica que obliga a muchos jóvenes espańoles a tener que buscar un trabajo en el extranjero, ni tampoco se presenta ninguna queja sobre el hecho de que un ingeniero tenga que trabajar de camarero.

Otro tímido ejemplo de problemas sociales son dos textos breves sobre una acción artística en las favelas de Río de Janeiro y sobre dos activistas que detuvieron un desahucio (Equipo Nuevo Prisma, 2015b, p. 9). No obstante, no se comenta explícitamente el fenómeno de las favelas o los desahucios ni tampoco conocemos los puntos de vista de los personajes que sufren estas situaciones problemáticas. En su lugar, la única perspectiva que se nos ofrece es una vez más la de personas con éxito: artistas y activistas que hicieron buenas acciones para los desfavorecidos.

Asimismo, cabe subrayar la anonimidad de los autores de estos libros de texto, que en la portada firman simplemente como Equipo Nuevo Prisma, sin que se mencionen sus nombres y apellidos. Esta anonimidad apunta a la falta de agentividad de los autores, que actualmente forman parte de una industria editorial lucrativa, la de ELE (Bruzos, 2017). Igualmente, es importante destacar que las editoriales hoy en día disponen de normas y 
pautas para los autores, que orientan de una forma más o menos rígida el contenido de los libros de texto (Kuzmanović Jovanović y Djuričić, 2015), lo que también disminuye la agentividad de los autores.

\subsection{Estrategias discursivas empleadas en el corpus}

A modo de síntesis del análisis del contenido, en la Tabla 1 presentamos un resumen de las principales estrategias discursivas sobre el concepto de clase y estratificación social identificadas en ambas colecciones.

TABLA I. RESUMEN DE ESTRATEgIAS DisCURSIVAS SOBRE LA CLASE SOCIAL

\begin{tabular}{|l|l|l|}
\hline $\begin{array}{l}\text { Estrategias } \\
\text { discursivas }\end{array}$ & \multicolumn{1}{|c|}{ Español en directo (1974-1977) } & \multicolumn{1}{|c|}{ Nuevo prisma (2013-2015) } \\
\hline Nominación & $\begin{array}{l}\text { Dos clases sociales en conflicto: } \\
\text { la capitalista y la trabajadora }\end{array}$ & $\begin{array}{l}\text { Una única clase social, la } \\
\text { meritocrática: la de los que } \\
\text { se esmeran y triunfan }\end{array}$ \\
\hline Predicación & $\begin{array}{l}\text { Abundancia y elitismo de la } \\
\text { clase capitalista ante las carencias } \\
\text { de la trabajadora; codicia de la } \\
\text { clase capitalista (y, en alguna } \\
\text { ocasión, de la trabajadora) }\end{array}$ & $\begin{array}{l}\text { Personajes exitosos que siguen } \\
\text { sus sueños, se esfuerzan y } \\
\text { arriesgan para conseguirlos }\end{array}$ \\
\hline Argumentación & $\begin{array}{l}\text { Insuficiencia salarial de la clase } \\
\text { trabajadora para el coste de la } \\
\text { vida; las relaciones capitalistas } \\
\text { de producción como causa } \\
\text { de la desigualdad social }\end{array}$ & $\begin{array}{l}\text { Importancia de ser emprendedor, } \\
\text { competitivo y flexible, } \\
\text { y de crearse una marca } \\
\text { personal; el sistema político- } \\
\text { económico no se cuestiona }\end{array}$ \\
\hline Perspectivización & $\begin{array}{l}\text { Explotación sufrida por la } \\
\text { clase trabajadora; ridiculez del } \\
\text { egoísmo de la clase trabajadora }\end{array}$ & $\begin{array}{l}\text { La visión del mundo } \\
\text { de los que triunfan }\end{array}$ \\
\hline $\begin{array}{l}\text { Intensificación/ } \\
\text { Mitigación }\end{array}$ & $\begin{array}{l}\text { Opulencia de la clase capitalista } \\
\text { ante la pobreza de la trabajadora }\end{array}$ & $\begin{array}{l}\text { Personas satisfechas, guapas, } \\
\text { sonrientes, con los rasgos de } \\
\text { clase totalmente borrados }\end{array}$ \\
\hline
\end{tabular}

\section{Conclusiones}

Los resultados del análisis de las estrategias discursivas sobre la clase social muestran que los libros de texto de ELE presentan visiones distintas de la realidad en diferentes momentos de la historia. Mientras que Español en directo, de la década de los setenta, hace énfasis en una sociedad dividida en dos clases y en el conflicto entre ellas, en la colección actual, Nuevo Prisma, predomina el discurso meritocrático, que borra la idea de una sociedad de clases. Este cambio en la representación de la clase social en los 
libros de texto se debe relacionar con la irrupción del neoliberalismo como paradigma ideológico dominante, el cual surge de las transformaciones de las condiciones económicas ocurridas en las últimas cuatro décadas en el sistema capitalista (Harvey, 2005).

A pesar de ser publicada en el marco de una sociedad capitalista, la colección de los setenta está influenciada en su representación de la clase por planteamientos marxistas, que en aquel entonces gozaban de una cierta popularidad, tanto entre la intelectualidad, como entre amplias capas de la sociedad. La visión sobre la clase social de esta colección invita a pensar en la lucha de clases y en la explotación que conlleva el capitalismo. En cambio, aunque las diferencias sociales entre ricos y pobres no han dejado de aumentar en los últimos años, la colección actual da a entender que la división por clases ya no existe y se convierte así en una correa de transmisión de la ideología neoliberal, con un discurso parecido al dominante en los medios de comunicación de masas y entre las elites económicas y políticas. Difunde la idea de que cualquier persona puede ascender en el ascensor social, siempre y cuando demuestre el suficiente talento y empeño para llegar adonde se proponga, sean cuales sean sus circunstancias sociales y económicas. Este discurso meritocrático, basado en el talento, el individualismo competitivo y el mito de la movilidad social, tiene como objetivo hacer aceptables las injusticas estructurales del capitalismo neoliberal (Littler, 2018). En otras palabras, la gente será más propensa a tolerar la desigualad si se sugiere que, a pesar de todo, la sociedad ofrece suficientes posibilidades para que todos tengan éxito (Littler, 2018). Sin embargo, como argumenta Littler (2018, p. 217), "la plena movilidad social [ ] no puede coexistir con una desigualdad extrema", ya que la disparidad de oportunidades entre la clase dominante y la subalterna impide por sí misma una auténtica fluidez social. El presente artículo espera haber arrojado luz a los mensajes de los libros de texto de ELE sobre el individuo y la sociedad, y, de esta forma, contribuir a una mayor concienciación entre profesorado, estudiantes, investigadores y autores de materiales didácticos sobre las connotaciones ideológicas de los libros de texto de idiomas.

\section{Apéndice: Libros de texto analizados}

- Sánchez, A., Ríos, M. y Domínguez, J. (1974, 1975). Español en directo Nivel 1A, 1B. Madrid: Ediciones Aravaca.

- Sánchez, A., Cabré, M. T. y Matilla, J. A. (1975, 1976). Español en directo Nivel $2 A, 2 B$. Madrid: Ediciones Aravaca.

- Sánchez, A. (1977). Español en directo Nivel 3. Madrid: Ediciones Aravaca.

- Equipo Nuevo Prisma (2013a, 2013b, 2015a, 2015b). Nuevo Prisma A1, A2, B1, B2. Madrid: Edinumen. 


\section{Referencias}

Apple, M. (2004). Ideology and curriculum ( $3^{a}$ ed.). Londres/ Nueva York: Routledge. Auerbach, E. R., y Burgess, D. (1985). The hidden curriculum of survival ESL. TESOL Quarterly, 19(3), 475-495.

Babaii, E., y Sheikhi, M. (2018). Traces of neoliberalism in English teaching materials: A critical discourse analysis. Critical Discourse Studies, 15(3), 247-64.

Block, D. (2014). Social class in applied linguistics. Londres: Routledge.

Block, D. (2015). Social class in applied linguistics. Annual Review of Applied Linguistics, 35, 1-19.

Block, D. (2018). Political economy and sociolinguistics: Neoliberalism, inequality and social class. Londres: Bloomsbury Publishing.

Block, D. y Gray, J. (2018). French language textbooks as ideologically imbued cultural artefacts: Political economy, neoliberalism and (self) branding. En S. Coffey y U. Wingate (Eds.), New directions for language learning in the 21st century (pp. 115-31). Londres: Routledge.

Bori, P. (2018). Language textbooks in the era of neoliberalism. Londres: Routledge.

Bori, P. (2019). Neoliberalisme en els llibres de text de català per a no catalanoparlants adults. Treballs de sociolingüistica catalana, 29: 105-118.

Bori, P. (2020). Neoliberal governmentality in global English textbooks. Classroom Discourse, 11(2), 149-163.

Bori, P., y Kuzmanović Jovanović, A. (en prensa). El mundo del trabajo en los libros de texto de ELE: Una perspectiva política y económica. Spanish in Context, 18 (2).

Bruzos, A. (2017). De camareros a profesores de ELE. La mercantilización del español y de su enseñanza como lengua extranjera. Spanish in Context, 14(2): 230-249.

Callinicos, A. (enero/ febrero 1995). ¿Qué es la clase trabajadora? Socialismo Internacional, 3. Recuperado de http://www.rebelion.org/noticia.php?id=173370.

Canagarajah, S. (2005). Critical pedagogy. En E. Hinkel (Ed.), Handbook of research in second language learning and teaching (pp. 931-50). Mahwah: Lawrence Erlbaum Associates.

Chapelle, C. A. (2016). Teaching culture in introductory foreign language textbooks. Basingstoke: Palgrave.

Chun, C. W. (2009). Contesting neoliberal discourses in EAP: Critical praxis in an IEP classroom. Journal of English for Academic Purposes, 8(2), 111-120.

Copley, K. (2018). Neoliberalism and ELT coursebook content. Critical Inquiry in Language Studies, 15(1), 43-62.

De Pablos-Ortega, C. (2018). Análisis y diseño de materiales didácticos. En J. Muñoz Basols, E. Gironzetti y M. Lacorte (Eds.), The Routledge handbook of Spanish language teaching (pp. 80-93). Londres: Routledge.

Fairclough, N. (1992). Discourse and social change. Londres: Polity.

Fairclough, N. (2014). Language and power. Londres: Routledge. 
Gray, J. (2010). The branding of English and the culture of the new capitalism: Representations of the world of work in English language textbooks. Applied Linguistics, 31(5), 714-733.

Gray, J. y Block, D. (2014). All middle class now? Evolving representations of the working class in the neoliberal era: The case of ELT textbooks. En N. Harwood (Ed.), English language teaching textbooks: Content, consumption, production (pp. 4571). Basingstoke: Palgrave.

Harvey, D. (2005). A brief history of neoliberalism. Oxford: Oxford University Press.

Hill, D. (2017). Social class and education. En D. O'Neill y M. Wayne (Eds.), Considering class: Theory, culture and the media in the 21st Century (pp. 31-50). Leiden: Brill.

Jones, O. (2016). Prólogo. En R. Romero y A. Tirado (Eds.), La clase obrera no va al paraíso: Crónica de una desaparición forzada (pp. 9-14). Madrid: Akal.

Kanno, Y. y Vandrick, S. (Eds.). (2014). Special forum: The role of social class in English language education [Número especial]. Journal of Language, Identity y Education, 13(2).

Kinginger, C. (2004). Alice doesn't live here anymore: Foreign language learning and identity reconstruction. En A. Pavlenko y A. Blackledge (Eds.). Negotiation of identities in multilingual contexts (pp. 219-42). Clevedon: Multilingual Matters.

Kuzmanović Jovanović, A. y Djuričić, M. (2015). Políticas lingüísticas sensibles al género y la deconstrucción de género en los manuales de ELE. Verba Hispánica, 23, 103-121.

Larner, W. (2000). Neo-liberalism: Policy, ideology, governmentality. Studies in Political Economy, 63(1), 5-25.

Littler, J. (2018). Against meritocracy. Nueva York: Routledge.

Marx, K., y Engels, F. (2018). The communist manifesto. Minneapolis: Lerner. (Obra original publicada el 1848).

Navarro, V. (2013). ¿Existen clases sociales? y ¿hay conflicto entre ellas? Recuperado de https://blogs.publico.es/vicenc-navarro/2013/09/17/existen-clases-socialeshayconflicto-entre-ellas/.

Wodak, R. (2007). Critical discourse analysis. En C. Seale, G. Gobo, J. F. Gubriumy, y D. Silverman (Eds.), Qualitative Research Practice (pp. 185-202). Londres: Sage. 